\title{
Emprego da Serapilheira Acumulada na Avaliação de Sistemas de Restauração Florestal em Alegre-ES
}

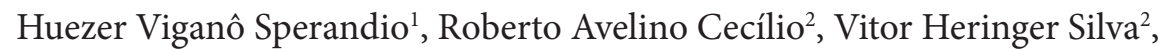 \\ George Fontes Leal ${ }^{2}$, Igor Batista Brinate ${ }^{2}$, Marcos Vinicius Winckler Caldeira ${ }^{2}$ \\ ${ }^{1}$ Programa de Pós-graduação em Ciências Florestais, Departamento de Ciências Florestais e da Madeira, \\ Universidade Federal do Espírito Santo - UFES, Jerônimo Monteiro/ES, Brasil \\ ${ }^{2}$ Departamento de Ciências Florestais e da Madeira, Universidade Federal do Espírito Santo - UFES, \\ Jerônimo Monteiro/ES, Brasil
}

\begin{abstract}
RESUMO
Objetivou-se, com o presente trabalho, quantificar a serapilheira acumulada em dois sistemas de restauração florestal implantados na Área de Relevante Interesse Ecológico "Laerth Paiva Gama", em Alegre-ES, comparando-os com uma área de mata nativa (MN). Os sistemas de restauração avaliados foram: consórcio entre eucalipto e acácias (REA) e sistema com espécies diversas (RED). A serapilheira foi coletada com auxílio de um coletor de $0,25 \mathrm{~m}^{2}$, realizando-se 16 repetições por sítio. Após a coleta, a serapilheira foi posta em estufa para secagem e determinação do peso de matéria seca. Os sistemas de restauração florestal apresentaram valores de serapilheira acumulada semelhantes à área de mata nativa, possuindo média geral de 5,61 $\mathrm{Mg} \mathrm{ha}^{-1}$. Ambos os sistemas responderam significativamente ao seu objetivo de implantação de deposição de serapilheira, não se evidenciando uma superioridade de um sistema em particular.
\end{abstract}

Palavras-chave: restauração com exóticas, floresta nativa, sustentabilidade.

\section{Employment of Litterfall in the Assessment of Forest Restoration Systems in Alegre, ES}

\begin{abstract}
The purpose of this study was to quantify the litterfall accumulated in two forest restoration systems deployed in the Area of Ecological Interest "Laerth Paiva Gama" in the municipality of Alegre, State of Espirito Santo, Brazil, by comparing them to the native forest (NF). The following restoration systems were evaluated: an intercropping system using eucalyptus and acacia (REA) and a system with diverse species (RDS). Litter was collected with the aid of a $0.25 \mathrm{~m}^{2}$ collector, performing 16 repetitions per site. After collection, the litter was put in oven for drying and determination of dry weight. The forest restoration systems showed values of accumulated litter similar to the native forest area, producing an overall average of $5.61 \mathrm{Mg} \mathrm{ha}^{-1}$. Both systems significantly reached their goals of litterfall deployment, with neither of them proving to be superior to the other.
\end{abstract}

Keywords: restoration with exotic species, native forest, sustainability.

\section{INTRODUÇÃO}

$\mathrm{Na}$ ocupação agrícola do território nacional, é observado um acelerado processo de exploração irracional dos recursos naturais, assim como a alteração ou a total substituição dos ecossistemas nativos. Segundo Lima et al. (2009), os modelos produtivos utilizados, dessa forma, vêm levando a 
uma crescente degradação dos recursos naturais, contribuindo para a redução da capacidade produtiva dos solos, associada a outros danos ambientais também de significativa importância.

A degradação de terras sob florestas representa uma significativa redução de sua capacidade produtiva, com a fragmentação de sua biodiversidade (Fearnside, 2005). Conforme Souza \& Alves (2003), a mudança na vegetação natural causa um desequilíbrio no ecossistema e as propriedades intrínsecas da nova vegetação influenciarão os processos físicos, químicos e biológicos do solo, modificando seus atributos e propiciando sua degradação. Contudo, é verificada, atualmente, uma grande pressão para amenização dos impactos antrópicos no meio natural, focando especialmente a recuperação de áreas degradas e a restauração florestal.

Barbosa \& Faria (2006) afirmam que, apesar da existência de diferentes modelos de repovoamento florestal heterogêneo para recuperação de áreas degradadas, nenhum pode ser considerado ideal para todos os casos de degradação. Isso é devido ao grande número de variáveis possíveis de interferir no desempenho das espécies, seja por características intrínsecas do local, seja pelo modelo adotado. Portanto, tornam-se imprescindíveis, para cada local, estudos que idealizem os modelos mais adequados e suas variáveis adaptativas para implantação. Franco et al. (1992) sugerem que, em sistemas de restauração florestal, devem-se sempre utilizar associações de espécies florestais que promovam não apenas rápido crescimento, mas que sejam capazes também de melhorar o solo por meio do aporte de serapilheira e a sua incorporação como matéria orgânica.

A serapilheira acumulada no solo corresponde ao reservatório de nutrientes e de matéria orgânica que influencia e regula muitos processos funcionais dos ecossistemas (Lopes et al., 1990). Os estudos deste compartimento, segundo Moraes et al. (1995), permitem que se conheçam vários aspectos das relações solo-planta, subsidiando propostas de manejo nas formações florestais.

Segundo Machado et al. (2008), no aporte da serapilheira insere-se ainda o seu acúmulo, que funciona como bom indicador ambiental. Neste sentido, diferentes são os trabalhos que empregam a serapilheira acumulada na avaliação de áreas em restauração florestal (Moreira \& Silva, 2004; Oliveira \& Ballestero, 2007; Machado et al., 2008; Klippel, 2011; Pimenta et al., 2011; Silva, 2012) e com diferentes manejos (Correa et al., 2006; Collier \& Araujo, 2010; Lima et al., 2010; Radomski \& Ribaski, 2012).

Além disso, a compreensão acerca da ciclagem de nutrientes é fundamental para o entendimento da dinâmica dos ecossistemas, uma vez que envolve o conhecimento do estoque e do fornecimento dos nutrientes à vegetação (Domingos et al., 1997).

Diante do exposto, o presente trabalho teve por objetivo quantificar a serapilheira acumulada em dois sistemas de restauração florestal e em uma Floresta Estacional Semidecidual, no município de Alegre, no Estado do Espírito Santo.

\section{MATERIAL E MÉTODOS}

A área de estudo constitui-se de três sítios experimentais situados no interior da Área de Relevante Interesse Ecológico "Laerth Paiva Gama" (ARIELPG), localizada no município de Alegre-ES. Os sítios experimentais foram demarcados conforme o uso do solo no local, a saber: mata nativa (MN), restauração florestal com eucalipto e acácia (REA), e restauração florestal com espécies diversas (RED) (Figura 1).

O clima local, segundo a classificação de Köppen, é do tipo Cwa. A topografia do terreno apresenta-se bastante ondulada, sendo inserido no denominado "Mar de Morros", e o soloé classificado como Latossolo Vermelho Amarelo (LVA). A Figura 2 apresenta o gráfico termopluviométrico de Alegre-ES, conforme os dados obtidos de Castro et al. (2010).

A área sob mata nativa (Figura 3) é caracterizada como Floresta Estacional Semidecidual que, segundo Veloso \& Góes-Filho (2003), apresenta uma estacionalidade foliar dos elementos arbóreos dominantes, possuindo aptidão fisiológica à deficiência hídrica ou à baixa temperatura, de acordo com as estações do ano. A MN é representada por um ambiente heterogêneo em termos de flora, com espécies arbóreas nativas, lianas e epífitas dominando a estrutura da paisagem. 


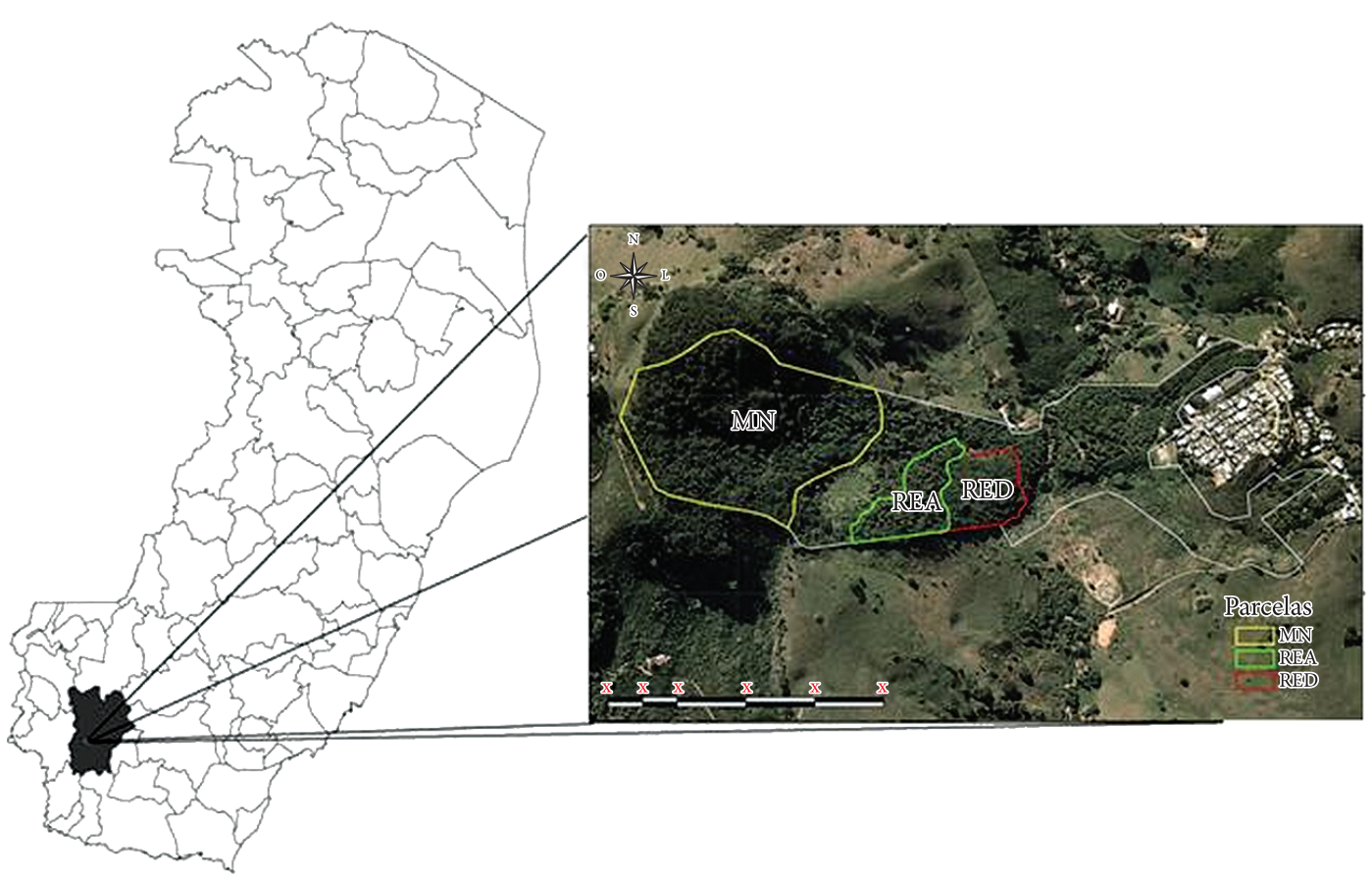

Figura 1. Localização e delimitação dos sítios em estudo (MN - Mata nativa, RED - Restauração com espécies diversas, REA - Restauração com eucalipto e acácias).

Figure 1. Location and delineation of the sites under study (MN - Forest native RED - Restoration with various species, REA - Restoration with eucalyptus and acacia).

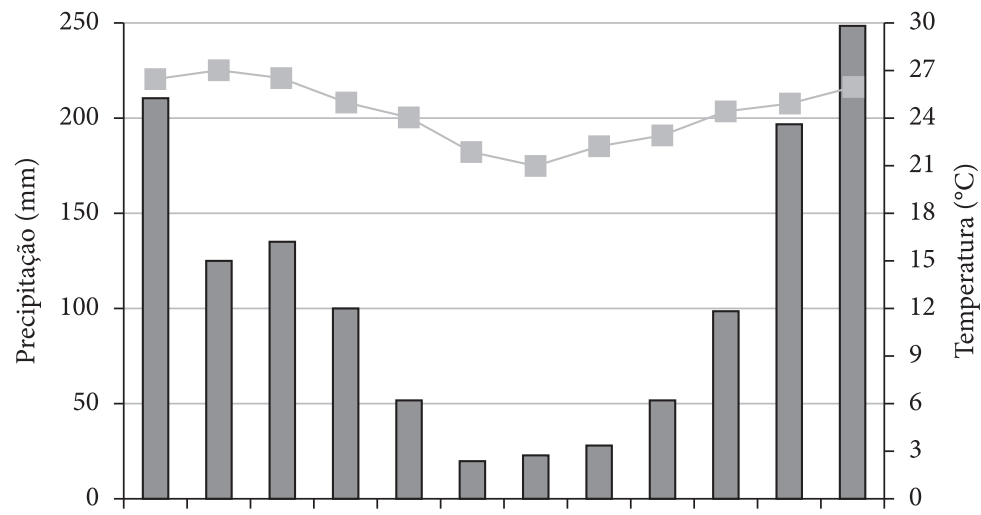

Jan. Fev. Mar. Abr. Maio Jun. Jul. Ago. Set. Out. Nov. Dez.

Figura 2. Gráfico termopluviométrico de Alegre-ES.

Figure 2. Graph of temperature and precipitation in the Alegre-ES.

As áreas definidas como de reflorestamento (REA e RED) foram ocupadas, em período anterior à década de 1950, com agricultura de culturas anuais (milho, feijão, arroz, dentre outras), tendo sido a área, posteriormente, destinada à monocultura do cafeeiro. Em 1992, foram implantados nesta área os dois sistemas de restauração florestal. $\mathrm{Na}$ REA (Figura 4), foram implantadas duas espécies exóticas (Eucalyptus sp., Acacia mangium Willd e Acacia auriculiformis A. Cunn. ex Benth.) e, na RED (Figura 5), foi implantado um bosque de espécies tropicais diversas. Em ambas, o plantio foi caracterizado por intercalar, de forma aleatória, as espécies, apresentando um espaçamento médio de $4 \times 5 \mathrm{~m}$. 

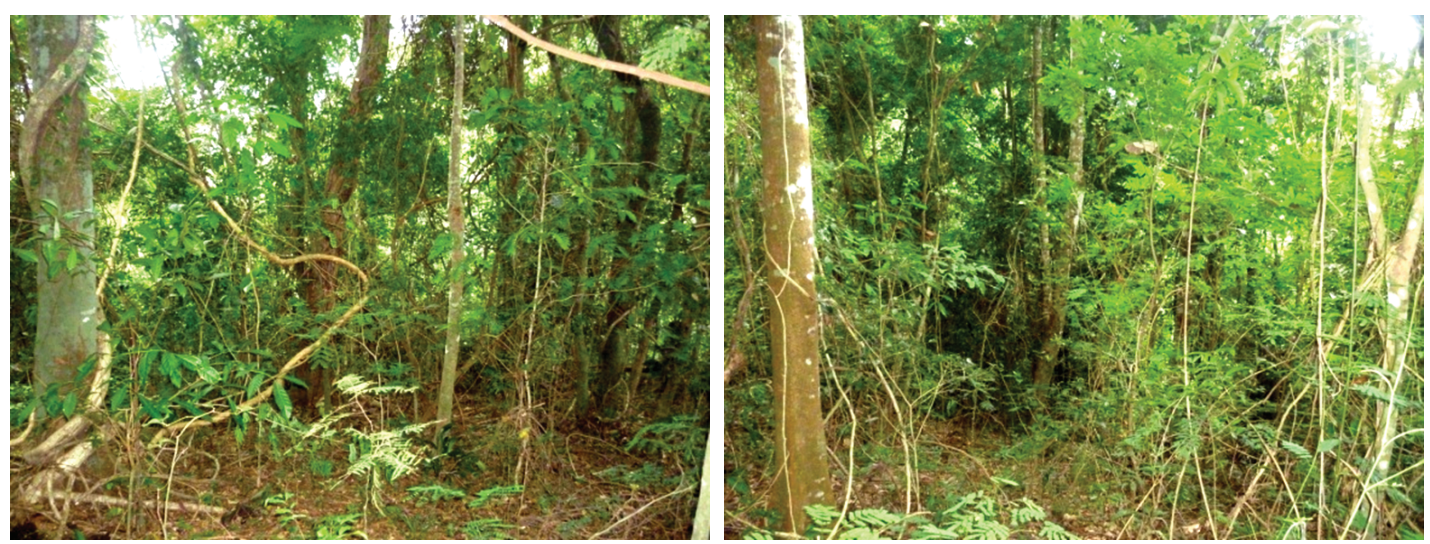

Figura 3. Vista parcial no interior da mata nativa.

Figure 3. Partial view inside the native forest.
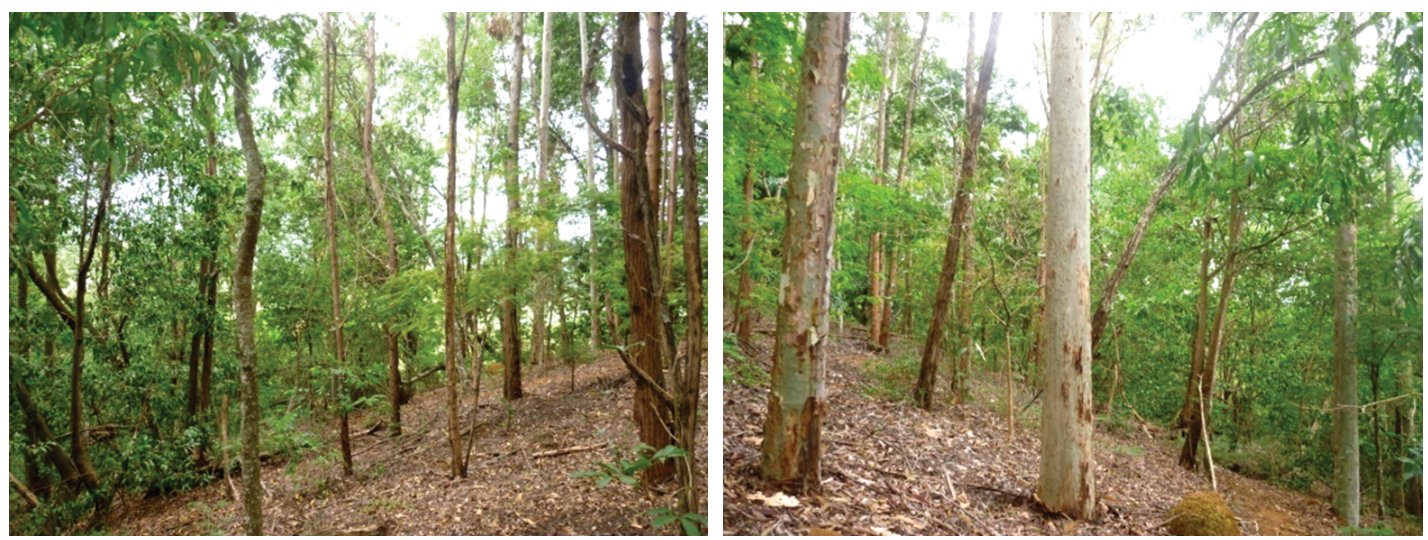

Figura 4. Vista parcial no interior do Reflorestamento com eucalipto e acácia.

Figure 4. Partial view inside the Reforestation with eucalyptus and acacia.
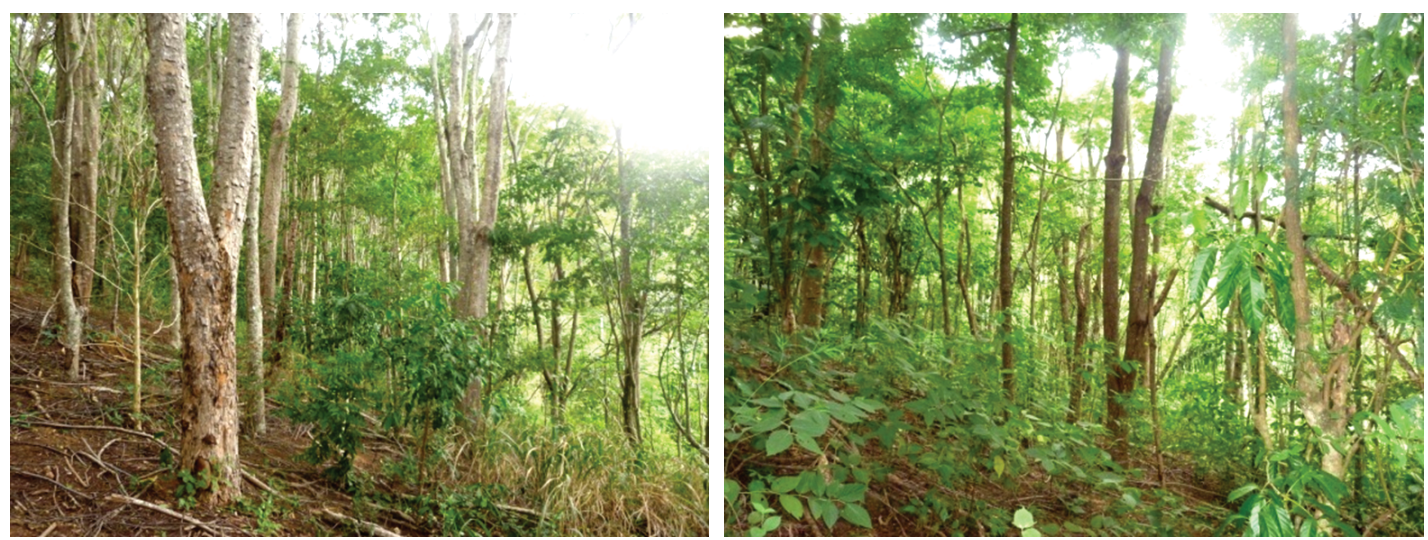

Figura 5. Vista parcial no interior do Reflorestamento com espécies diversas.

Figure 5. Partial view inside the Reforestation with various species.

A coleta da serapilheira acumulada foi realizada no mês de junho de 2010, com o auxílio de um gabarito de formato quadrangular $\left(0,25 \mathrm{~m}^{2}\right)$. O gabarito, em campo, foi colocado na superfície do terreno, conforme a declividade do local, e todo o material orgânico presente em seu interior foi 
coletado e armazenado em sacos de papel. Os sacos com a serapilheira coletada foram conduzidos ao Laboratório de Ecologia Florestal da Universidade Federal do Espírito Santo e inseridos em estufa de circulação fechada e renovação de ar a $65^{\circ} \mathrm{C}$, até alcançar massa seca constante. Posteriormente, o material foi pesado para obtenção da massa de matéria seca da serapilheira.

Em cada sítio, foram realizadas 16 coletas, de forma aleatória, em seu interior. Os dados foram submetidos à análise de variância pelo teste $\mathrm{F}$ e foi aplicado o teste de Tukey no nível de $5 \%$ de probabilidade.

\section{RESULTADOS E DISCUSSÃO}

Conforme observado na Figura 6, os valores de serapilheira acumulada nos pisos florestais não diferiram estatisticamente entre si, apresentando média geral para os sítios em estudo igual a $5,61 \mathrm{Mg} \mathrm{ha}^{-1}$.

Os valores de serapilheira acumulada determinados são semelhantes aos apresentados por Cunha (1997), em trabalho com biomassa da serapilheira acumulada em Floresta Estacional no Estado do Rio Grande do Sul, em diferentes estágios de sucessão: capoeira com 13 anos, capoeirão com 19 anos e floresta secundária com mais de 30 anos, tendo sido encontrados os seguintes valores: 4,2 $\mathrm{Mg} \mathrm{ha}^{-1}$, 5,6 $\mathrm{Mg} \mathrm{ha}^{-1}$ e 6,0 $\mathrm{Mg} \mathrm{ha}^{-1}$, respectivamente. Tais valores mostram-se, contudo, inferiores aos encontrados por Diniz \& Pagano (1997) e Durigan et al. (1996), que observaram 11,59 $\mathrm{Mg} \mathrm{ha}^{-1}$ e 11,12 $\mathrm{Mg} \mathrm{ha}^{-1}$, respectivamente, em Floresta Estacional Semidecidual no interior do Estado de São Paulo. Klippel (2011), trabalhando com diferentes modelos de restauração florestal para a Mata Atlântica, em Linhares-ES, observou média de biomassa de serapilheira acumulada de 7,4 Mg ha ${ }^{-1}$, sendo que o modelo testado com a inserção da leguminosa Sesbania grandiflora apresentou biomassa de 9,1 $\mathrm{Mg} \mathrm{ha}^{-1}$.

Silva (2012), estudando o comportamento da serapilheira acumulada em sistemas de restauração florestal em Alegre-ES, encontrou uma média de 10,33 e $7,74 \mathrm{Mg} \mathrm{ha}^{-1}$, para os períodos chuvoso e seco, respectivamente. O valor para o período seco encontra-se próximo aos deste estudo, realizado também em período seco, no mesmo município.

Estudos específicos em ambientes tropicais reportam variações de 3,6 a 12,4 $\mathrm{Mg} \mathrm{ha}^{-1}$ de matéria seca na forma de serapilheira acumulada (Correia \& Andrade, 2008). Nas condições climáticas do sul do Espírito Santo, um estudo conduzido por Effgen (2008), em área ocupada pela monocultura do eucalipto, e outros trabalhos, de Gonçalves (2008) e Godinho (2011), em Mata Atlântica, encontraram valores de serapilheira acumulada iguais a 5,4; 7,51;

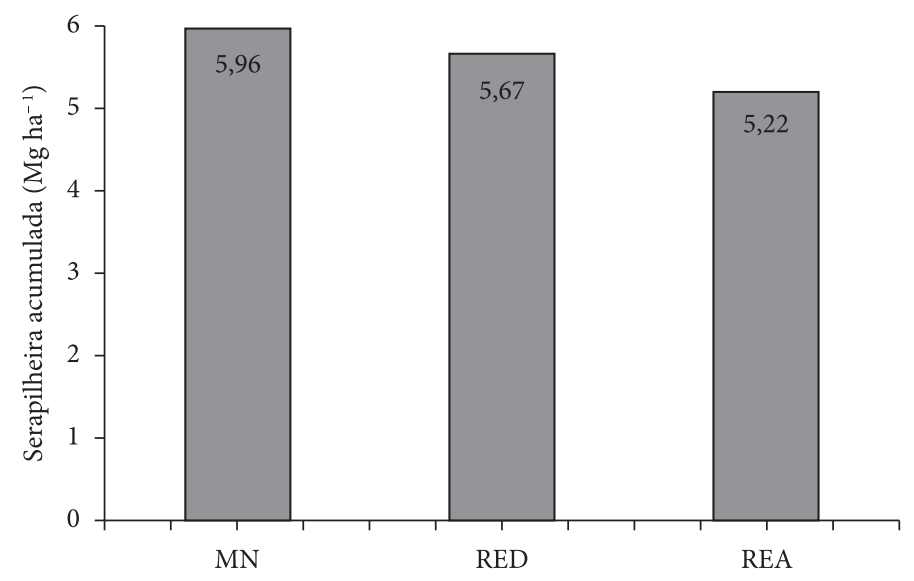

Figura 6. Médias para a serapilheira acumulada no piso florestal dos sítios em estudo ( $M N$ - Mata nativa, RED - Restauração com espécies diversas e REA - Restauração com eucalipto e acácia) no município de Alegre-ES. Figure 6. Averages for the forest floor litter accumulated in the sites under study (MN - Forest native, RED - Restoration with diverse species and REA - Restoration with eucalyptus and acacia) in the municipality of Alegre-ES. 
9,26 $\mathrm{Mg} \mathrm{ha}^{-1}$, respectivamente, sendo estes próximos aos encontrados para a REA e a $\mathrm{MN}$, no presente estudo.

A presença do eucalipto na REA, segundo Cortines et al. (2005), tende a fornecer um nível estável de cobertura do solo durante todo o ano, em virtude da maior resistência da serapilheira aos processos de degradação e ciclagem de nutrientes, pois o eucalipto possui folhas e galhos com grandes concentrações de lignina e celulose. Há, ainda, a presença de acácia, que apresenta grande potencial de aporte de matéria orgânica e, assim como o eucalipto, sua serapilheira apresenta baixa taxa de decomposição.

De maneira geral, conforme Leitão Filho (1993), o ambiente florestal tropical apresenta uma estabilidade na produção de serapilheira no decorrer do ano, em função do seu estado clímax; note-se que a quantidade de serapilheira produzida nas diferentes épocas depende do tipo de vegetação considerada. Balbinot et al. (2003) elucidam que, no início do estabelecimento de florestas naturais e plantações florestais, a produção de serapilheira é baixa, vai aumentando com a idade e pode, posteriormente, ocorrer redução, no seu estado clímax.

$\mathrm{Na}$ observação dos valores quantificados para serapilheira na área em estudo, deve-se levar em consideração que o local está situado em um pequeno fragmento florestal, afetado diretamente pelos usos do solo no seu entorno. Esta situação, segundo Correia \& Andrade (2008), provoca um significativo efeito de borda, levando a alterações na colonização vegetal e nas condições microclimáticas, as quais, consequentemente, acabam por interferir no aporte da serapilheira. Tais diferenças podem, ainda, ser explicadas pelo fato de que a serapilheira acumulada nos solos florestais pode variar significativamente entre diferentes espécies estabelecidas no mesmo sítio (O’Connelle \& Sankaran, 1997). Segundo Caldeira et al. (2007), outros fatores podem influenciar as caracteríaticas da serapilheira, tais como: o baixo nível de nutrientes na serapilheira e no solo; as condições desfavoráveis para a decomposição, como déficit de água no solo e na serapilheira; o pH alto ou baixo, e a baixa densidade da população de organismos decompositores, além da época de coleta, bem como da estação do ano.

Os sistemas de restauração florestal avaliados (REA e RED) possuem padrões satisfatórios no que tange à introdução de serapilheira no sistema local, visto que sua presença melhora as condições do solo, por minimizar o impacto das gotas de chuva, e ameniza a temperatura do solo, além de, em sua decomposição, favorecer os processos de ciclagem de nutrientes e promover, assim, uma melhoria da qualidade do solo.

Verifica-se que ambos os sistemas de restauração florestal apresentaram a mesma interferência sobre a cobertura orgânica depositada no solo, evidenciando uma equiparação dos sistemas e não ocorrendo, dessa forma, uma ascendência de um sistema específico.

\section{CONCLUSÕES}

Os sistemas de restauração florestal avaliados apresentaram valores de serapilheira acumulada semelhantes aos da mata nativa, possuindo média geral de 5,61 $\mathrm{Mg} \mathrm{ha}^{-1}$.

Ambos os sistemas de restauração florestal responderam significativamente ao seu objetivo de implantação de deposição de serapilheira, não se evidenciando uma superioridade de um sistema em particular.

\section{AGRADECIMENTOS}

À Prefeitura Municipal de Alegre-ES, por autorizar a coleta de material na ARIELPG, e ao CNPQ, pela concessão de Bolsas de Mestrado e de Produtividade.

\section{STATUS DA SUBMISSÃO}

Recebido: 18/11/2011

Aceito: 01/10/2012

Publicado: $31 / 12 / 2012$

AUTOR(ES) PARA CORRESPONDÊNCIA

\section{Huezer Viganô Sperandio}

Engenheiro Florestal. Mestrando em Ciências

Florestais. Departamento de Ciências Florestais e da Madeira, Universidade Federal do Espírito Santo - UFES, Av. Governador Lindemberg, 316, Centro, CEP 29550-000, Jerônimo Monteiro, ES, Brasil

e-mail: huezer@gmail.com 


\section{REFERÊNCIAS}

Balbinot R, Schumacher MV, Watzlawick LF. Inventário do carbono orgânico em um plantio de Pinus taeda aos 5 anos de idade no Rio Grande do Sul. Revista de Ciências Exatas e Naturais 2003; 5: 59-68.

Barbosa JHC, Faria SM. Aporte de serapilheira ao solo em estágios sucessionais florestais na reserva biológica de Poço das Antas, RJ, Brasil. Rodriguésia 2006; 57: 461-476.

Caldeira MVW, Marques R, Soares RV, Balbinot R. Quantificação de serrapilheira e de nutrientes - Floresta Ombrófila Mista Montana - Paraná. Revista Acadêmica Ciências Agrárias e Ambientais 2007; 5: 101-116.

Castro FS, Pezzopane JEM, Cecilio RA, Pezzopane JRM, Xavier AC. Avaliação do desempenho dos diferentes métodos de interpoladores para parâmetros do balanço hídrico climatológico. Revista Brasileira de Engenharia Agrícola e Ambiental 2010; 14: 871-880. http://dx.doi. org/10.1590/S1415-43662010000800012

Collier LS, Araujo GP. Fertilidade do Solo sob Sistemas de Produção de Subsistência, Agrofloresta e Vegetação Remanescente em Esperantina-Tocantins. Floresta $e$ Ambiente 2010; 17(1):12-22. http://dx.doi.org/10.4322/ floram.2011.005

Correia MEF, Andrade AG. Formação de serrapilheira e ciclagem de nutrientes. In: Santos GA, Silva LS, Canellas L, Camargo FAO, organizadores. Fundamentos da matéria orgânica do solo-ecossistemas tropicais e subtropicais. Porto Alegre: Metrópole; 2008.

Correa FLO, Ramos JD, Gama-Rodrigues AC, Muller MW. Produção de serapilheira em sistema agroflorestal multiestratificado no Estado de Rondônia, Brasil. Ciência e Agrotecnologia 2006; 30(6):1099-1105. http:// dx.doi.org/10.1590/S1413-70542006000600008

Cortines E, Magalhães MAF, Melo AL, Valcarcel R. Monitoramento da regeneração como forma de avaliar a auto-sustentabilidade da recuperação de ecossistemas perturbados e com exíguos atributos ambientais de Nova Iguaçú, RJ. In: Anais do VI Simpósio Nacional sobre áreas degradadas, Anais do II Congresso Latino Americano de recuperação de áreas degradadas; 2005; Curitiba. Curitiba: UFPR; 2005. p. 345-354.

Cunha GC. Aspectos da ciclagem de nutrientes em diferentes fases sucessionais de uma Floresta Estacional do Rio Grande do Sul [dissertação]. Piracicaba: Escola Superior de Agricultura Luiz de Queiroz; 1997.

Diniz S, Pagano SN. Dinâmica de folhedo em floresta mesófila semidecídua no município de Araras, SP. I-Produção, deposição e acúmulo. Revista do Instituto Florestal 1997; 9: 27-36.

Domingos M, Moraes RM, De Vuono YS, Anselmo CE. Produção de serapilheira e retorno de nutrientes em um trecho de Mata Atlântica secundária, na Reserva Biológica de Paranapiacaba, SP. Revista Brasileira de Botânica 1997; 20: 91-96. http://dx.doi.org/10.1590/ S0100-84041997000100009

Durigan G, Leitão-Filho HF, Pagano SN. Produção de folhedo em matas ciliares na Região Oeste do Estado de São Paulo. São Paulo. Revista do Instituto Florestal 1996; 8: 187-199.

Effgen EM. Avaliação de Atributos Físicos e Químicos de um Latossolo Vermelho-Amarelo Distrófico sob Cultivo de Eucalipto e Pastagem no Sul do Espírito Santo [dissertação]. Alegre: Universidade Federal do Espírito Santo; 2008.

Fearnside PM. Desmatamento na Amazônia brasileira: história, índices e consequências. Megadiversidade 2005; 1: 113-123.

Franco AA, Campello EF, Silva EMR, Faria SM. Revegetação de solos degradados. Seropédica: EMBRAPA-CNPAB; 1992.

Godinho TO. Quantificação de biomassa e de nutrientes na serapilheira em trecho de floresta estacional semidecidual submontana, Cachoeiro de Itapemirim, ES [dissertação] Jerônimo Monteiro: Universidade Federal do Espírito Santo; 2011.

Gonçalves MAM. Avaliação da serrapilheira em fragmento de floresta atlântica no sul do estado do Espírito Santo [dissertação] Alegre: Universidade Federal do Espírito Santo; 2008.

Klippel VH. Avaliação de métodos de restauração florestal de Mata Atlântica de Tabuleiros [dissertação] Jerônimo Monteiro: Universidade Federal do Espírito Santo; 2011.

Leitão-Filho HF. Ecologia da Mata Atlântica em Cubatão. Campinas: Unesp, Unicamp; 1993.

Lima JS, Sattler MA, Passos RR, Oliveira PC, Souza GS. Variabilidade espacial de atributos físicos de um argissolo vermelho-amarelo sob pastagem e vegetação secundária em regeneração natural. Engenharia Agrícola 2009; 29: 185-195.

Lima SS, Leite LFC, Aquino AM, Oliveira FC, Castro AAJF. Serapilheira e teores de nutrientes em argissolo sob diferentes manejos no norte do Piauí. Revista Árvore 2010; 34(1):75-84. http://dx.doi.org/10.1590/ S0100-67622010000100009

Lopes MIMS, Vuono YS, Domingos M. Serapilheira acumulada na Floresta da Reserva Biológica de Paranapiacaba, sujeita aos poluentes atmosféricos de Cubatão, SP. Hoehnea 1990; 17: 59-70.

Machado MR, Rodrigues FCMP, Pereira MG. Produção de serapilheira como bioindicador de recuperação em plantio adensado de revegetação. Revista Árvore 2008; 32(1)143-151. http://dx.doi.org/10.1590/ S0100-67622008000100016 
Moraes RM, De Vuono YS, Domingos M. Aspectos da decomposição da serapilheira em florestas preservadas e sujeitas à poluição atmosférica, no Estado de São Paulo, Brasil. Hoehnea 1995; 22: 91-100.

Moreira PR, Silva OA. Produção de serapilheira em área reflorestada. Revista Árvore 2004; 28(1): 49-59. http:// dx.doi.org/10.1590/S0100-67622004000100007

O'Connell AM, Sankaran KV. Organic matter accretion, decomposition and mineralisation. In: Nambiar EKS, Brown AG, editors. Management of soil, nutrients and water in tropical plantations forests. Canberra: ACIAR Australia/CSIRO; 1997. p. 443-480.

Oliveira L, Ballestero SD. Recuperação do solo em povoamentos florestais em área de exploração de areia no município de Tremembé-SP. Revista de Biociências 2007; 13(3)156-166.

Pimenta JA, Rossi LB, Torezan JMD, Cavalheiro AL, Bianchini E. Produção de serapilheira e ciclagem de nutrientes de um reflorestamento e de uma floresta estacional semidecidual no sul do Brasil. Acta Botanica Brasilica 2011; 25(1)53-57.

Radomski MI, Ribaski J. Fertilidade do solo e produtividade da pastagem em sistema silvipastoril com Grevillea robusta. Pesquisa florestal brasileira 2012; 32(69):53-61.

Silva RD. Indicadores de recuperação ambiental em diferentes coberturas florestais, Alegre-ES [dissertação]. Jerônimo Monteiro: Universidade Federal do Espírito Santo; 2012.

Souza ZM, Alves MC. Propriedades químicas de um latossolo vermelho distrófico de cerrado sob diferentes usos e manejos. Revista Brasileira de Ciência do Solo 2003; 27: 133-139. http://dx.doi.org/10.1590/ S0100-06832003000100014

Veloso HP, Goes-Filho L. Fitogeografia Brasileira: Classificação Fisionômica-Ecológica da Vegetação Neo Tropical - Projeto RADAMBRASIL. Salvador; 1982. Série Vegetação. 